\title{
Working in the Sky: A Diary Study on Work Engagement Among Flight Attendants
}

\author{
Despoina Xanthopoulou \\ and Arnold B. Baker \\ Erasmus University Rotterdam
}

\author{
Ellen Heuven, Evangelia Demerouti, \\ and Wilmar B. Schaufeli \\ Utrecht University
}

\begin{abstract}
This study aims to gain insight in the motivational process of the Job Demands-Resources (JD-R) model by examining whether daily fluctuations in colleague support (i.e., a typical job resource) predict day-levels of job performance through self-efficacy and work engagement. Forty-four flight attendants filled in a questionnaire and a diary booklet before and after consecutive flights to three intercontinental destinations. Results of multilevel analyses revealed that colleague support had unique positive effects on self-efficacy and work engagement. Self-efficacy did not mediate the relationship between support and engagement, but work engagement mediated the relationship between self-efficacy and (in-role and extra-role) performance. In addition, colleague support had an indirect effect on in-role performance through work engagement. These findings shed light on the motivational process as outlined in the JD-R model, and suggest that colleague support is an important job resource for flight attendants helping them reach their work-related goals.
\end{abstract}

Keywords: colleague support, Job Demands-Resources model, performance, self-efficacy, work engagement

Which working conditions make employees flourish and help them reach their work-related goals? Several studies have shown that job resources such as autonomy, task identity and social support may function as initiators of a process that leads to work engagement and performance (for reviews, see Bakker \& Demerouti, 2007; Fried \& Ferris, 1987). Some authors emphasize the role of self-efficacy in explaining the transition from job resources to positive psychological and organizational outcomes (Gist \& Mitchell, 1992; Luthans, Avey, Avolio, Norman, \& Combs, 2006). However, this mediating effect has received only limited empirical support with regard to work engagement. The present study among flight attendants uses the Job Demands-Resources (JD-R) model

Despoina Xanthopoulou and Arnold B. Bakker, Institute of Psychology, Department of Work \& Organizational Psychology, Erasmus University Rotterdam, Woudestein, Rotterdam, The Netherlands; Ellen Heuven, Evangelia Demerouti, and Wilmar B. Schaufeli, Department of Social and Organizational Psychology, and Research Institute Psychology \& Health Utrecht University, Utrecht, The Netherlands.

Correspondence concerning this article should be addressed to Despoina Xanthopoulou, Erasmus University Rotterdam, Institute of Psychology, Department of Work and Organizational Psychology, Woudestein, T12-56, P. O. Box 1738, 3000 DR, Rotterdam, The Netherlands. E-mail: xanthopoulou@fsw.eur.nl
(Bakker \& Demerouti, 2007) as a guiding framework to examine whether colleague support predicts performance, through the enhancement of employees' self-efficacy beliefs and work engagement. In contrast to previous studies that exclusively focused on how individuals differ from one another, we use a diary approach and a multilevel design, which takes into account both betweenperson and within-person variations.

\section{The Motivational Process of the JD-R Model}

Job resources are those physical, psychological, social or organizational aspects of the job that: (1) are functional in achieving work goals; (2) reduce job demands and the associated costs; and/or (3) stimulate personal growth, learning and development (Demerouti, Bakker, Nachreiner, \& Schaufeli, 2001). Put differently, resources are those job characteristics that are instrumental for the attainment of the work goals, and whose absence hinders the attainment of these goals and the presumed personal growth (Hackman \& Oldham, 1980). According to the JD-R model, job resources are not only necessary to deal with job demands, but they contribute uniquely to employees' wellness. Particularly, job resources initiate a motivational process that may lead to high work engagement and performance (Bakker \& Demerouti, 2007). 
Job resources have both intrinsic and extrinsic motivational potential (Bakker \& Demerouti, 2007). As intrinsic motivators, job resources, by meeting basic human needs, foster individuals' growth and development (Deci \& Ryan, 1985). For instance, colleague or supervisory support satisfies the basic need for belonging. As extrinsic motivators, job resources promote employees' willingness to exert effort toward their tasks (Gagné \& Deci, 2005). In both cases, the increased likelihood of completing the tasks successfully induces a feeling of fulfillment in employees (Hackman \& Oldham, 1980) that boosts their work engagement (i.e., a work-related state of mind that is characterized by vigor, dedication and absorption; Schaufeli, Salanova, González-Romá, \& Bakker, 2002). Work engagement, in turn, may produce positive organizational outcomes, like enhanced performance (for a review, see Schaufeli \& Salanova, 2007). Considering that engagement is an affectivemotivational indicator of work-related well-being (Schaufeli \& Salanova, 2007), this proposition corresponds with the happy-productive worker (HPW) thesis, which states that happiness, particularly when operationalized as positive affect, is a robust predictor of job performance (Cropanzano \& Wright, 2001).

The motivational process of the JD-R model has received substantial empirical support in studies that followed a between-person approach. For example, Schaufeli and Bakker (2004) found evidence for the relationship between feedback, colleague support and coaching on the one hand, and work engagement on the other hand, in a multisample study. Also, Llorens, Bakker, Schaufeli, and Salanova (2006) demonstrated the robustness of the motivational process by showing that the mediating role of work engagement in the relationship between job resources (i.e., control, support, feedback) and organizational commitment was invariant across samples and countries (The Netherlands and Spain). Nevertheless, there is only limited evidence so far regarding lagged effects of job resources on work engagement (Llorens, Schaufeli, Bakker, \& Salanova, 2007).

Consistent with the HPW thesis, general levels of employees' work engagement have been found to predict business-unit performance (Harter, Schmidt, \& Hayes, 2002), as well as client-rated performance (Salanova, Agut, \& Peiró, 2005). In a similar vein, Schaufeli, Taris, and Bakker (2006b) supported the link between work engagement and in-role performance, namely activities that are related to employees' formal role requirements (Borman \& Motowidlo, 1997). In addition, Bakker, Demerouti, and
Verbeke (2004) used the JD-R model and found that job resources, through (dis)engagement, predicted extra-role performance. In other words, engaged employees are also more likely to perform activities that are not part of their formal role requirements, but nevertheless promote organizational effectiveness (Borman \& Motowidlo, 1997).

\section{The Mediating Role of Self-Efficacy}

In an attempt to explore the psychological mechanism that underlies the relationship between job resources and positive psychological and organizational outcomes, the present study focuses on workrelated self-efficacy, namely employees' estimates of their capacity to orchestrate performance on a specific task (Gist \& Mitchell, 1992). Self-efficacy is a vital personal resource because it affects human functioning (Bandura, 2000). According to Hobfoll's (1989) conservation of resources theory, people who hold resources do not only strive to protect these resources, but also to accumulate them. Since resources do not exist in isolation, developmental processes create "resources caravans" in a way that, for example, individuals working in a resourceful environment are likely to increase their beliefs in their capabilities (Hobfoll, 2002). When people become convinced that they have what it takes to succeed, they persevere in the face of adversity, and consequently develop a stronger sense of self-efficacy (Bandura, 1989). Therefore, a resourceful work environment, which facilitates the attainment of work goals, may activate employees' beliefs regarding their capabilities to fulfill these goals. As a result, employees may show higher levels of work engagement, and in turn, perform better.

There is plenty of empirical evidence regarding the positive effect of self-efficacy on individual choices, goals, emotional reactions, effort, coping and persistence (for a review, see Gist \& Mitchell, 1992). Empirical studies also support the relationship between specific types of self-efficacy and various performance outcomes (Lubbers, Loughlin, \& Zweig, 2005; for a meta-analysis, see Stajkovic \& Luthans, 1998). However, there are fewer studies that examine potential antecedents of self-efficacy, as well as its mediating role in the relationship between the work environment and positive psychological and organizational outcomes. Regarding the determinants of self-efficacy, Parker (1998) showed, using a longitudinal analysis in a manufacturing company, that job resources, like task control and 
quality of communication, predicted the development of task-related self-efficacy.

With regard to the mediating role of self-efficacy, Saks (1995) supported, in a three-wave study, that post training self-efficacy mediated the relationship between training and job satisfaction, commitment, and turnover intentions. Similarly, Luthans et al. (2006) suggested that training boosting job resources (e.g., goal setting, goal clarification or quality feedback) may increase employees' "psychological capital," whose central dimension is self-efficacy. There is preliminary support that such interventions may bring financial profit and high return on investment (Luthans et al., 2006). Finally, to our knowledge, there is only one longitudinal study that examined the mediating role of efficacy beliefs with regard to the motivational process of the JD-R model (Llorens et al., 2007). This two-wave study showed that professional efficacy played a mediating role between task resources (i.e., method and time control) and work engagement. However, this study concerned students and thus needs to be replicated among employees for ecological validity reasons. To conclude, self-efficacy seems to be an important process variable for understanding the relationship between job resources and positive psychological and organizational outcomes. However, more empirical evidence is needed, particularly in the context of the motivational process of the JD-R model.

\section{The Present Study}

The majority of the supportive studies on the motivational process of the JD-R model have taken measurements of work engagement and performance at one point in time, despite the presumed importance of lagged effects (Wright \& Cropanzano, 2000; Yeo $\&$ Neal, 2004). In addition, recent studies have also started to investigate momentary episodes of work engagement (Sonnentag, 2003) and performance (Beal, Weiss, Barros, \& MacDermid, 2005), and concluded that meaningful variations exist not only at the between-person, but also at the within-person level. Therefore, the purpose of the present study is to test, for the first time, how variations in job resources may determine state levels of work engagement, through the enhancement of employees' state self-efficacy beliefs over time. Moreover, the same between- and within-person design is used to examine the process from state job resources to state in-role and extra-role performance, through state self-efficacy and work engagement. States reflect how an individual feels about him/herself and the environment at certain points in time, and as such are highly fluctuant. Thus, evidence for these relationships at the within-person level would further support the validity of the motivational process of the JD-R model, because it would suggest that the same psychological mechanisms apply, even when conditions change. While examining these within-person processes, it is imperative to control for employees' global (i.e., rather stable) levels of work engagement and performance, because the way employees generally react with regard to their work may also affect their momentary states (George, 1991).

The current study focuses on flight attendants. There is an increased interest in this specific occupational group, which may be explained by the special contextual factors that characterize this occupation (Guzzo \& Dickson, 1996). One of the most significant factors is the limited duration of flight crew's existence as a unit. Flight crews work together for a limited period of time (i.e., going to and returning from a certain destination), after which members are reassigned to other flight crews. Flight attendants need to develop relationships with their colleagues quickly, a process that is facilitated by the standard preflight briefing. Due to this particularity, it is obvious that there is a high variability with regard to the levels of support that flight attendants receive from their colleagues, during each trip, which makes this specific job resource a crucial predictor of flight attendants' state levels of engagement and performance. Due to the potential variability and presumed significance of colleague support for flight attendants (Bacharach, Bamberger, \& McKinney, 2000), we focus exclusively on this specific job resource. Moreover, because flight attendants are often exposed to emotion work (e.g., emotionally charged interactions with passengers; Heuven, Bakker, Schaufeli, \& Huisman, 2006), we examine an emotional type of colleague support, which refers to affective participation, empathy, liking or respect (House, 1981). Finally, the design of the present study (see Table 1) allows testing lagged effects, because the predictor (support), the mediator (selfefficacy) and the outcome variables (work engagement and performance) were measured at different, successive points in time.

\section{Study Hypotheses}

Based on our theoretical analysis, we predict that state colleague support will have a positive effect on state work engagement, through the me- 
Table 1

The Study Design

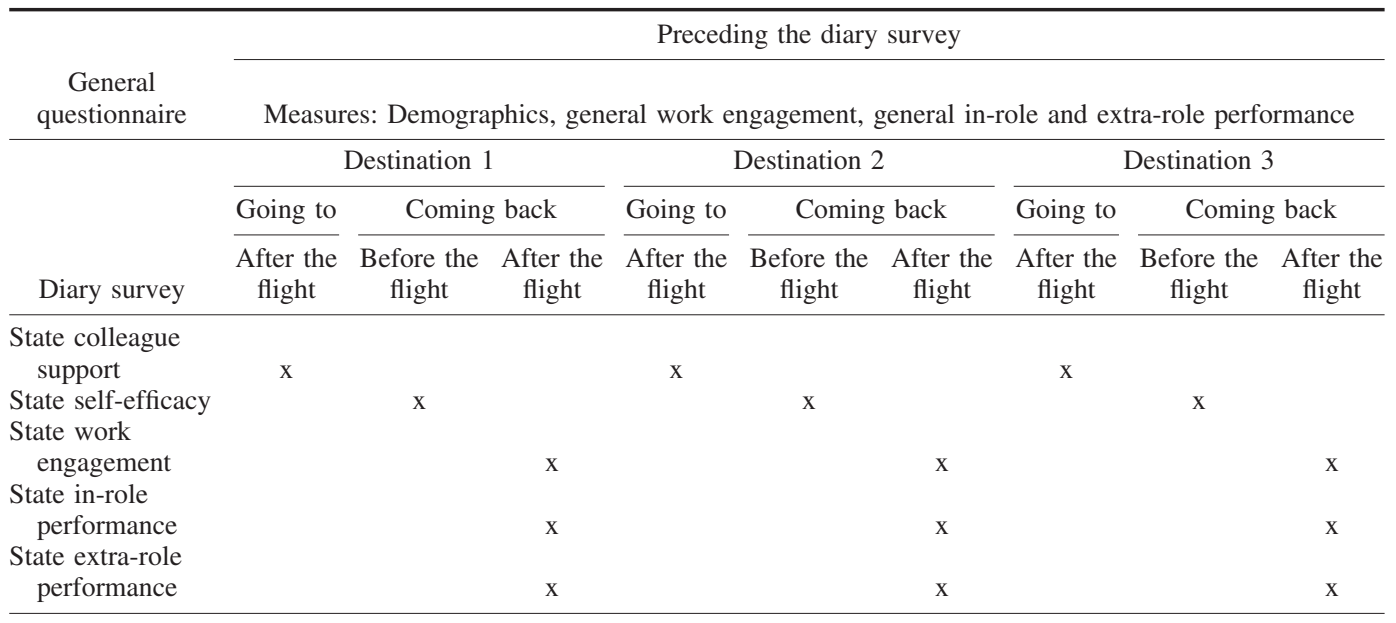

Note. Time points at which each variable was measured are indicated with an $\mathrm{x}$.

diation of state self-efficacy, after controlling for general levels of work engagement (Hypothesis 1). In addition, state colleague support will be positively related to in-role (Hypothesis $2 a$ ) and extrarole (Hypothesis $2 b$ ) performance through the subsequent mediation first of state self-efficacy and then of state work engagement, after controlling for general levels of work engagement and performance.

\section{Method}

\section{Procedure and Participants}

Flight attendants from a European airline company participated in the study. A general questionnaire was handed out to a randomly selected sample of 700 flight attendants. In total, 222 flight attendants participated (response of 32\%). These 222 employees were then asked to take part in a diary survey. Eightythree flight attendants agreed to participate (response of $38 \%$ ). These employees were given a package that included a diary booklet, instructions about the completion of the diary, and return envelopes. Employees were asked to fill in the diary over three consecutive trips to three intercontinental destinations, including six stretches (outbound flights to and inbound flights from the destination). In each pair of flights, participants had to work with different crews. Each pair of flights is considered as one study occasion. Between each outbound and each inbound flight, crews had few days off, which is a common practice for recovery reasons. Table 1 presents in detail the study design and time points at which each variable was measured.

Data was collected during the period of three months. Employees were asked to fill in the number of their company postbox on the questionnaire sheet and on the diary booklet. In this way, participants' anonymity was assured and researchers were able to match the questionnaires and the diary surveys for each employee. Employees returned the questionnaires and diaries by mail after completion. A total of 52 diaries were returned (63\% response rate). In eight of these diaries participants did not fill in their postbox number, and we were unable to match their diaries with the general questionnaires. Thus, 44 general questionnaires and diaries could be used for the current study. Preliminary analyses revealed that this final sample did not differ significantly from the remaining sample that only participated in the initial questionnaire study $(N=178)$ regarding the demographics: gender: $F(1,214)=.30, p=.58$, age: $F(1$, 214) $=1.70, p=.19$, tenure: $F(1,214)=3.15, p=$ .08 , education: $F(1,214)=1.64, p=.20$, general work engagement, $F(1,215)=3.20, p=.08$, and performance (in-role: $F(1,215)=.06, p=.81$; extra-role: $F(1,215)=.01, p=.94)$. The total sample included $39(89 \%)$ women and $5(11 \%)$ men. The age of the majority of the participants (73\%) varied from 25 to 44 years, and half of the sample (52\%) had an organizational tenure of more 
than nine years. Finally, $68 \%$ of the sample held a college degree.

\section{Measures}

Questionnaire data. General Work Engagement was assessed with the nine-item version of the Utrecht Work Engagement Scale (UWES; Schaufeli, Bakker, \& Salanova, 2006a). The UWES items reflect three underlying dimensions, which are measured with three items each: Vigor (e.g., "At my work, I feel bursting with energy"), Dedication (e.g., "I am enthusiastic about my job"), and Absorption (e.g., "I get carried away when I am working"). Items were scored on a seven-point scale, ranging from $0=$ never to 6 = always. We followed Schaufeli et al.'s (2006a) recommendation, and we computed an overall work engagement factor score of the UWES ( $\alpha=$ .89 ), which we used in further analyses.

General In-Role Performance was measured with three items of Goodman and Svyantek (1999). An example item is "I achieve the objectives of my job". Participants were asked to indicate the extent to which each statement characterizes them on a sevenpoint scale $(0=$ not at all characteristic, $6=$ totally characteristic; $\alpha=.80)$.

General Extra-Role Performance was also assessed with three items of Goodman and Svyantek's (1999) instrument (e.g., "I willingly attend functions not required by the organization, but help in its overall image"; $\alpha=.69$ ). The same answer categories as for in-role performance were used.

Diary data. The diary assessed state measures of support, self-efficacy, work engagement, and performance. These measures reflect persons' levels on these characteristics on the specific occasions tested. All state measures were rated on a seven-point scale $(1=$ no, I totally disagree, to $7=y e s, I$ totally agree). Diary survey items were selected from validated and reliable scales on the basis of their face validity for the particular study.

State Colleague Support was measured with the item "During today's flight, my colleagues showed personal interest in me", which reflects emotional support (House, 1981). This item was deduced from the colleague support scale developed by Karasek (1985). Unpublished analyses on a diary data set $(N=55)$ collected before the present study, showed that the particular item correlated .55 to .60 across the study occasions with the total score of the state social support scale. Additional analyses showed that the specific item intercorrelated .63 to .73 with other emotional support items.
State Work-Related Self-Efficacy was measured with four items (e.g., "Right now, I feel that I can handle whatever happens on board today") based on Schwarzer and Jerusalem's (1995) self-efficacy scale. Cronbach's alphas across the three occasions ranged from .80 to $.91(M=.86)$.

State Work Engagement was measured with 12 items adapted from the 17-item version of the UWES (Schaufeli et al., 2002). We included four items for vigor (e.g., "Today, I was able to continue working for a long period of time"), five items for dedication (e.g., "Today, I felt proud on the work I did") and three items for absorption (e.g., "Today, I was completely immersed in my work"). We again computed an overall work engagement factor score (Schaufeli et al., 2006a) for each of the three occasions. Cronbach's $\alpha$ s ranged from .79 to $.85(M=.81)$ across occasions. The original items of the UWES were modified in order to fit in the context of the particular study design (i.e., within-person, flight attendants). To prevent potential reliability and validity problems, we included more items for work engagement in the diary survey than in the general questionnaire.

State In-Role Performance was measured with two items ("Today, I performed well", and "Today, I fulfilled all the requirements for my job") based on Goodman and Svyantek (1999). Cronbach's as across the three occasions ranged from .76 to .91 $(M=.84)$, and inter-item correlations ranged from .63 to .84 .

State Extra-Role Performance was also assessed with two items ("Today, I voluntarily did more than was required of me", and "Today, I helped my colleagues when they had too much work to do") adapted from Goodman and Svyantek (1999). Cronbach's $\alpha$ s across the three occasions ranged from .62 to $.85(M=.76)$, and inter-item correlations ranged from .53 to .75 .

\section{Results}

Our data may be viewed as multilevel data, with repeated measurements nested within individuals. This leads to a two-level model with the repeated measurements at the first-level $(N=132$ occasions), and the individual persons at the secondlevel ( $N=44$ participants). The MlwiN software (version 1.10.006) (Rashbash, Browne, Healy, Cameron, \& Charlton, 2000) was used for testing the study hypotheses. For our analyses, first (day)level predictor variables were centered on the respective person mean, and second-level variables were centered on the grand mean. 
Table 2

Means, SDs, and Correlations Among the Study Variable $(\mathrm{N}=44)$

\begin{tabular}{|c|c|c|c|c|c|c|c|c|c|c|c|c|c|c|}
\hline & $M$ & $S D$ & 1 & 2 & 3 & 4 & 5 & 6 & 7 & 8 & 9 & 10 & 11 & 12 \\
\hline 1 Gender & 1.11 & .32 & - & & & & & & & & & & & \\
\hline 2 Age & 2.90 & .80 & .05 & - & & & & & & & & & & \\
\hline 3 Tenure & 3.05 & 1.14 & .11 & $.57^{* *}$ & - & & & & & & & & & \\
\hline 4 Education & 2.16 & .99 & -.06 & -.01 & -.09 & 一 & & & & & & & & \\
\hline $\begin{array}{l}5 \text { General work } \\
\text { engagement } \\
6 \text { General in-role }\end{array}$ & 4.09 & .97 & -.01 & -.11 & $-.35^{*}$ & -.24 & - & & & & & & & \\
\hline $\begin{array}{l}\text { performance } \\
7 \text { General extra-role }\end{array}$ & 4.90 & .75 & -.09 & .00 & -.05 & -.03 & $.58^{* *}$ & - & & & & & & \\
\hline $\begin{array}{l}\text { performance } \\
8 \text { State colleague }\end{array}$ & 4.45 & .92 & -.10 & -.19 & -.17 & -.03 & $.39^{*}$ & $.53^{* *}$ & - & & & & & \\
\hline support & 5.68 & 1.20 & .05 & -.05 & -.10 & .02 & .30 & .18 & .13 & - & & & & \\
\hline $\begin{array}{l}9 \text { State self-efficacy } \\
10 \text { State work }\end{array}$ & 6.02 & .73 & -.04 & .29 & .19 & .11 & .33 & $.43^{*}$ & .17 & .24 & - & & & \\
\hline $\begin{array}{l}\text { engagement } \\
11 \text { State in-role }\end{array}$ & 4.67 & .68 & -.05 & -.18 & -.01 & .24 & .12 & .13 & .04 & $.37^{*}$ & .28 & - & & \\
\hline $\begin{array}{c}\text { performance } \\
12 \text { State extra-role }\end{array}$ & 6.25 & .52 & -.14 & -.07 & .07 & .21 & $.48^{* *}$ & $.53^{* *}$ & .15 & .22 & $.66^{* *}$ & $.39^{*}$ & - & \\
\hline performance & 5.88 & .96 & -.12 & -.18 & -.02 & .16 & .28 & .28 & $.45^{* *}$ & .19 & .11 & $.39^{*}$ & .33 & - \\
\hline
\end{tabular}

Note. All demographics are categorical variables; first-level data was averaged across the three occasions.

${ }^{* * *} p<.01 .{ }^{*} p<.05$.

\section{Descriptive Statistics}

Table 2 presents the means, standard deviations and correlations among the study variables. Demographic characteristics were not significantly related with any of the dependent variables (see Table 2) and thus were excluded from further analyses.

\section{Variability Over Time}

To determine the amount of variance that is attributed to the different levels of analysis, we calculated the intraclass correlation for each first-level variable (Hox, 2002). Results revealed that $57 \%$ of variance in colleague support and $62 \%$ in self-efficacy could be attributed to between-person variation. Furthermore, $59 \%$ of the variance in work engagement, $44 \%$ in in-role performance, and $40 \%$ in extra-role performance could be attributed to between-person variation. These analyses suggest that there are significant proportions of variance left to be explained by within-person fluctuations, supporting the application of multilevel analysis.

\section{Testing Hypothesis 1: Self-Efficacy as a Mediator}

According to Hypothesis 1, state self-efficacy mediates the relationship between state colleague sup- port and state work engagement, after controlling for general levels of work engagement. Multilevel analyses supported all prerequisite conditions for testing mediation (Baron \& Kenny, 1986). Colleague support was significantly related to both work engagement, $t=2.38, p<.05$ and self-efficacy, $t=1.98$, $p<.05$, and self-efficacy was significantly related to work engagement, $t=3.46, p<.001$. To Test Hypothesis 1, we examined the four nested models presented in Table 3.

Table 3 shows that the inclusion of state selfefficacy in Model 3 turned the previous significant relationship between colleague support and work engagement into non significance, $t=1.77, p=$ .08. Furthermore, Model 3 was the best fitting model to our data, since its value of deviance $(\Delta-2 \times \log )$ was significantly lower in comparison with the previous models. However, application of the Sobel test indicated that this mediating effect was not significant $(z=1.57, p=.12)$. Thus, Hypothesis 1 is rejected.

\section{Testing Hypothesis 2 ( $a$ and $b$ ): Predicting Performance}

In order to test the effect of colleague support on in-role (Hypothesis 2a) and extra-role (Hypothesis 
Table 3

Multilevel Estimates for Models Predicting Day-Level Work Engagement: Day-Level Self-Efficacy as Mediator ( $\mathrm{N}=132$ Occasions, $\mathrm{N}=44$ Participants)

\begin{tabular}{|c|c|c|c|c|c|c|c|c|c|c|c|c|}
\hline \multirow{2}{*}{$\begin{array}{c}\text { Model } \\
\text { Variables }\end{array}$} & \multicolumn{3}{|c|}{ Null } & \multicolumn{3}{|c|}{1} & \multicolumn{3}{|c|}{2} & \multicolumn{3}{|c|}{3} \\
\hline & Estimate & $S E$ & $t$ & Estimate & $S E$ & $t$ & Estimate & $S E$ & $t$ & Estimate & $S E$ & $t$ \\
\hline Intercept & .017 & .134 & .127 & .015 & .126 & .119 & -.776 & .404 & -1.921 & -2.345 & .719 & $-3.261^{* * *}$ \\
\hline $\begin{array}{l}\text { General work } \\
\text { engagement }\end{array}$ & & & & .321 & .134 & $2.396^{*}$ & .269 & .130 & $2.069^{*}$ & .157 & .132 & 1.189 \\
\hline $\begin{array}{l}\text { State colleague } \\
\text { support }\end{array}$ & & & & & & & .139 & .068 & $2.044^{*}$ & .117 & .066 & 1.772 \\
\hline $\begin{array}{l}\text { State self- } \\
\text { efficacy }\end{array}$ & & & & & & & & & & .286 & .111 & $2.577^{*}$ \\
\hline$-2 \times \log$ & & & 284.16 & & & 278.67 & & & 274.68 & & & 268.18 \\
\hline$\Delta-2 \times \log$ & & & & & & $5.49^{*}$ & & & $3.99^{*}$ & & & $6.50^{*}$ \\
\hline$d f$ & & & & & & 1 & & & 1 & & & 1 \\
\hline & & & & & & $R^{2}$ & & & $R^{2}$ & & & $R^{2}$ \\
\hline $\begin{array}{l}\text { Level } 1 \\
\quad \text { (within- } \\
\text { person) } \\
\text { Variance }\end{array}$ & .409 & .070 & & .405 & .069 & $1 \%$ & .405 & .069 & $1 \%$ & .388 & .065 & $5 \%$ \\
\hline $\begin{array}{l}\text { Level } 2 \\
\quad \text { (between- } \\
\text { person) } \\
\text { variance }\end{array}$ & .597 & .167 & & .520 & .150 & $13 \%$ & .457 & .136 & $23 \%$ & .417 & .127 & $30 \%$ \\
\hline
\end{tabular}

2b) performance through the mediation of selfefficacy and work engagement, we followed a similar procedure as for Hypothesis 1. Preliminary analyses revealed that colleague support was not a significant predictor of either in-role, $t=1.22, p=.22$, or extra-role, $t=1.37, p=.17$ performance. Nevertheless, results indicated that state self-efficacy was significantly related to both in-role, $t=5.70, p<$ .001 , and extra-role $(t=3.09, p<.01)$ performance. Furthermore, work engagement was a significant predictor of in-role, $t=4.98, p<.001$, and extra-role $(t=3.50, p<.001)$ performance. The finding that colleague support is not related with either in-role or extra-role performance partly rejects Hypotheses 2a and $2 \mathrm{~b}$. In cases where total effects are absent and hypotheses of mediation are rejected, the alternative hypotheses of the indirect effect of colleague support on in-role and extra-role performance should be examined (Mathieu \& Taylor, 2006). Nonetheless, in line with the initial hypotheses, it is still possible to examine whether work engagement mediates the relationships between selfefficacy and the two types of performance.

In order to Test Hypothesis 2a, we applied four models similar to testing Hypothesis 1 (see Table 4). Results showed that work engagement partially me- diated the relationship between self-efficacy and inrole performance, since the magnitude of the direct relationship became significantly weaker after the inclusion of the mediator $(t=3.26, p<.001 ; z=$ $2.50, p<.05)$. Also, results of the Sobel test showed that colleague support had an indirect effect on inrole performance through work engagement $(z=$ 1.99, $p<.05)$, but not through self-efficacy $(z=$ $1.69, p=.09)$.

To Test Hypothesis $2 \mathrm{~b}$, we applied the same four models that we used for testing Hypothesis 2a, with the difference that in Model 1 we controlled for general extra-role performance instead of general in-role performance. Analyses revealed (see Table 5) that work engagement fully mediated the relationship between self-efficacy and extra-role performance, since the previously significant relationship turned to nonsignificance after the mediator was added to the model $(t=1.76, p=.08, z=$ 2.24, $p<.05)$. The Sobel test did not confirm an indirect effect of colleague support either through work engagement $(z=1.85, p=.06)$ or self-efficacy $(z=1.32, p=.19)$. Taken together, the above results provide partial support for Hypotheses $2 \mathrm{a}$ and $2 \mathrm{~b}$. 


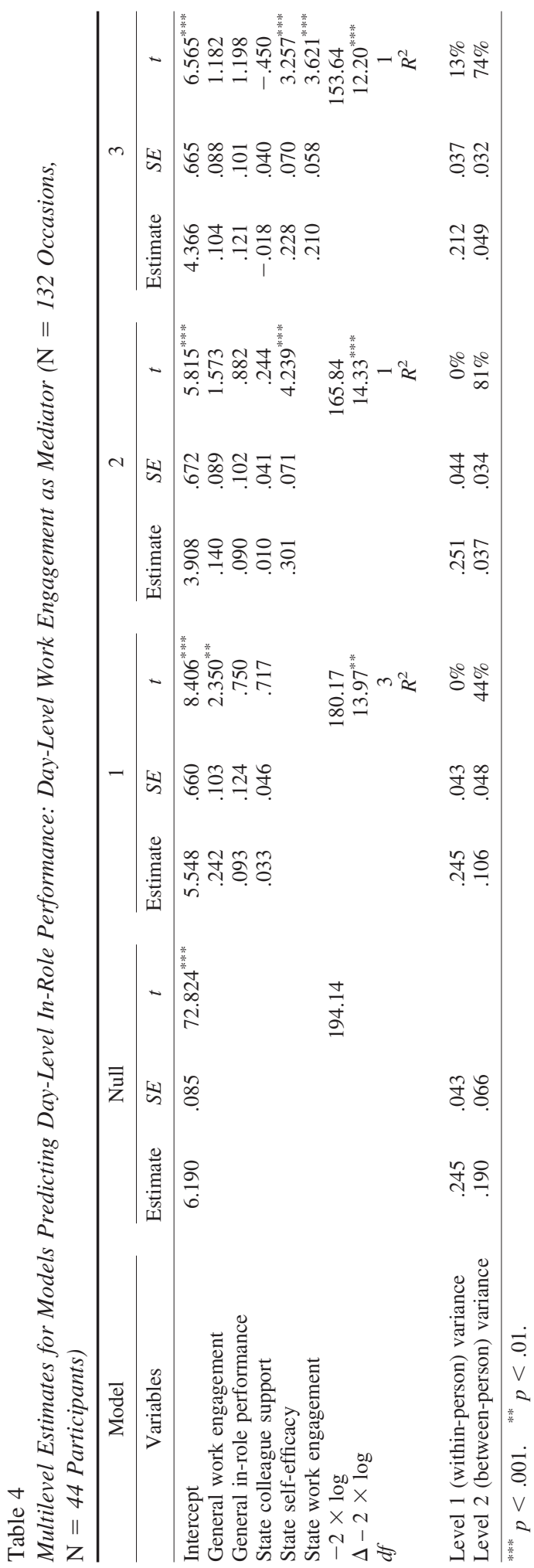

\section{Discussion}

The aim of the present study was to test betweenand within-person variations with regard to the motivational process of the JD-R model (Bakker \& Demerouti, 2007). Additionally, the mediating role of self-efficacy in the relationship between colleague support on the one hand, and work engagement and performance on the other hand was investigated. The present study makes two important contributions. First, our findings confirm the motivational process of the JD-R model as they show that a supportive work environment not only enhances employees' work engagement, but also their work-related selfefficacy beliefs. Second, results suggest that colleague support and self-efficacy are related to performance, through work engagement. The innovativeness of the study is that it examined timevarying predictors of state outcomes, thus capturing the dynamic character of the processes under study (Wright \& Cropanzano, 2000).

\section{The Motivational Process of the JD-R Model}

Results of the present study supported the motivational process of the JD-R model by showing that colleague support enhances flight attendants' work engagement. This finding is in line with previous studies on the JD-R model at the between-person level (Llorens et al., 2006; Schaufeli \& Bakker, 2004). However, the present study is the first to provide evidence for short-term, positive lagged effects of colleague support on work engagement. The additional contribution of the present study is that it treats colleague support as a time-varying predictor of state work engagement thus suggesting that although its levels may fluctuate from one day to the other, support is related to work engagement.

In line with Gist and Mitchell (1992), who proposed that apart from internal factors (e.g., skills), also external factors (e.g., the amount of resources required to perform a task) influence self-efficacy, our findings showed that colleague support was positively related with self-efficacy. In other words, employees who work in a supportive environment are more likely to believe that they have sufficient resources to complete their tasks successfully. Consequently, feelings of self-efficacy are likely to increase. Most importantly, Gist and Mitchell (1992) noted that the degree of change that might be expected in self-efficacy is related to how variable its determinants are. This is in accordance with our study's design, which supported 


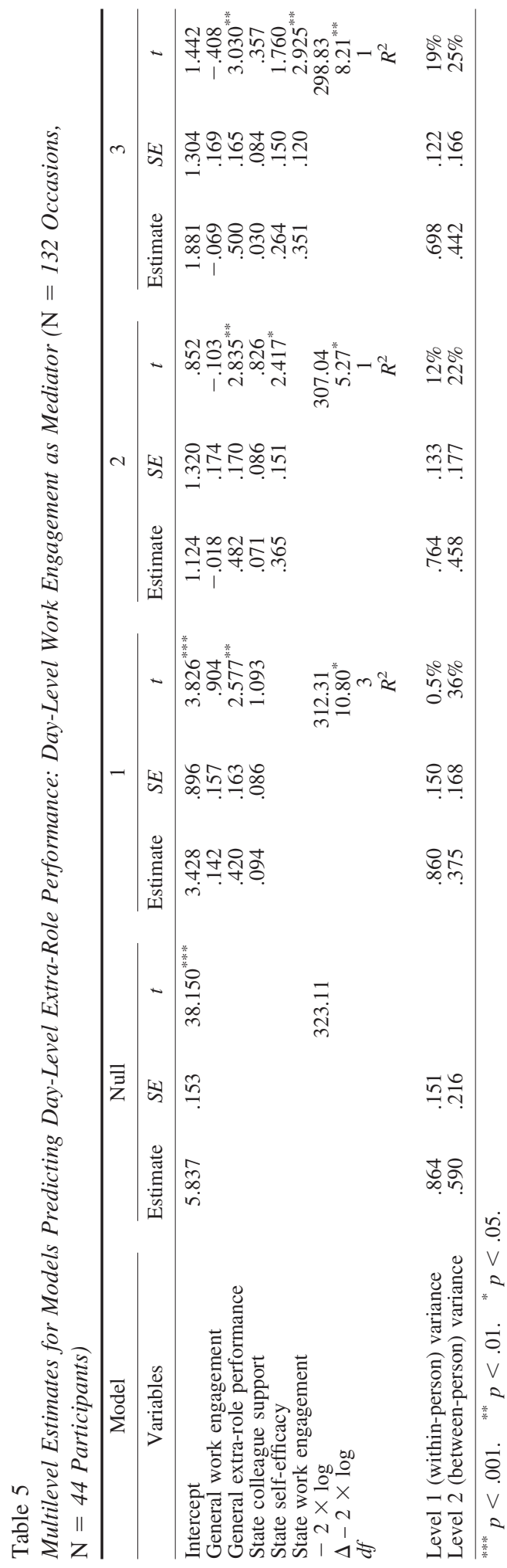

that self-efficacy levels are highly dependent on the levels of colleague support. The above findings are also consistent with the study of Helmreich and Wilhelm (1991) on the effectiveness of flight crew resource management training. These researchers have shown that training focused on the creation of a resourceful work environment (e.g., acquisition of appropriate information, or improvement of interpersonal activities and leadership) leads to positive changes in crew members' attitudes about both coordination and self-efficacy. Nevertheless, self-efficacy did not mediate the relationship between colleague support and work engagement. Although the direct effect from support to work engagement turned into nonsignificance after the inclusion of self-efficacy in the equation, the decrease in the magnitude of the direct effect was not significant. Considering that this mediating effect is theoretically important, future studies should reexamine this nonsignificant finding.

\section{Predicting In-Role and Extra-Role Performance}

Contrary to our second hypothesis, social support was not a significant predictor of in-role and extrarole performance. Previous studies also failed to provide evidence for the direct effect of support on job performance. For instance, results of a study that included several job resources showed that social support was not significantly correlated with either in-role or extra-role performance, whereas opportunities for professional development appeared to be the strongest correlate (Bakker et al., 2004). Nevertheless, our analyses showed that colleague support was related to in-role performance indirectly through work engagement. Although evidence for mediation is theoretically more important because it sheds light on the nature of the relationship that exists between two variables, support for indirect effects is also of interest since it provides information about the sequence of effects (Mathieu \& Taylor, 2006). Thus, our findings suggest that support indirectly affects performance due to the fact that it is a strong initiator of engagement.

Our analyses indicated that work-related selfefficacy was related to both in-role and extra-role performance, through employees' work engagement. When flight attendants believe that they are able to deal effectively with their work requirements, it is more likely that they are willing to put more effort in the task. In turn, they show higher levels of vigor, 
dedication and absorption in their work, which consequently leads to better performance. As Bandura (1997) proposes, performing well is not only a matter of skills, but also it has to do with how confident employees are about the skills that they already have. Further, the degree to which employees are engaged in their job, also determines whether self-efficacy beliefs will be transformed to high performance. The present findings expand previous studies that supported the relationship between general levels of selfefficacy and work engagement in flight attendants (Heuven et al., 2006), by underlying its state character, and its effect on performance episodes (Beal et al., 2005).

The finding that work engagement mediates the relationship between self-efficacy and performance supports and expands the HPW thesis (for a review, see Cropanzano \& Wright, 2001). Having in mind that work engagement is conceived as a state of work-related well-being (Schaufeli \& Salanova, 2007), our study is of the few to detect potential state antecedents of state work wellness (Ilies, Schwind, \& Heller, 2007). Finally, our findings expand previous research among employees who work together in short-lived groups (for a review see, Guzzo \& Dickson, 1996), by accentuating the role of state job and personal resources in their state well-being and performance.

\section{Limitations}

The current study exclusively focused on flight attendants, which limits the generalizability of the findings. Furthermore, the fact that colleague support was measured with only one item may be considered problematic. Although single-item measures are easier and take less time to complete (an important parameter for diary studies), they are usually more susceptible to errors than multi-item measures. It is recommended that future studies will use multi-item scales in order to increase the internal consistency of the tests. Moreover, although the study design allowed to test lagged effects, not all variables were assessed at all measurement points. Thus, we were unable to take auto-regressions into account. Nevertheless, our study design, by introducing time lags, strengthens causal inference (Daniels \& Harris, 2005) and thus it is superior to cross-sectional designs.

The small number of employees who participated in the diary study may raise questions of selective bias. However, there were no significant differences between our final sample and the sample that initially participated in the survey. Besides, by controlling for general levels of work engagement, we ruled out any potential biasing effect due to potential positive affectivity within our sample. Furthermore, this study was exclusively interested in psychological processes and not in comparisons of groups or means, where the use of representative samples is of crucial importance. It is also worth mentioning that low response rates are very often observed in studies with flight attendants (Heuven \& Bakker, 2003; Heuven et al., 2006). Finally, the study was based on self-ratings of performance, which due to their subjectivity, may be biased. However, our findings are in line with previous (between-person) studies, which used objective estimations of performance (Bakker et al., 2004; Stajkovic \& Luthans, 1998). We should keep in mind that other-ratings of performance may be problematic as well (i.e., halo effect; Viswesvaran, Schmidt, \& Ones, 2005), while in many cases (including cabin personnel) it is almost impossible to test objective outcomes that are meaningful indicators of individual performance.

\section{Practical Implications and Avenues for Future Research}

The present study suggests that the empowerment of colleague support should be a significant component of organizational interventions and crew training programs (Helmreich \& Wilhelm, 1991). Previous studies showed that giving and receiving support at work is reciprocal (Bowling, Beehr, \& Swader, 2005). Thus, it is proposed that organizations should emphasize to employees that a way to increase the receipt of support is actually to give support. Supporting each other may be beneficial, not only because it makes flight attendants more confident to deal with difficult tasks, but also because it creates a positive work environment. Moreover, our findings are significant beyond the context of flight attendants. According to the main principles of the JD-R model (Demerouti et al., 2001), we expect that the same psychological mechanisms apply in all occupational settings, but maybe for different types of job resources, depending on the context.

Our findings suggest that organizations should also focus on the fostering of employees' positive selfbeliefs. According to Bandura (2000) there are specific techniques (i.e., instructive modeling, guided skill perfection, and transfer training by self-directed success) that aim at the cultivation of self-efficacy. Moreover, in the present study work-related selfefficacy was found to be highly fluctuant and to vary 
from day to day (cf. $38 \%$ within-person variance). Thus, it is important that the implementation of efficacy enhancement programs should be in time proximity to the tasks that the employees have to fulfill, in order to be successful (Stajkovic \& Luthans, 1998). In case of flight attendants, such short-run programs could take place during the preflight briefing.

Together with self-efficacy, other personal resources, such as self-esteem or optimism, may also play a crucial role in the understanding of employees' adaptation in their work environments (Hobfoll, 2002; Luthans et al., 2006). Therefore, it is imperative that future studies will also examine the role of other personal resources in the motivational process of the JD-R model. It is important that research in this area uses such an integrated theoretical framework, as well as between- and within-person designs, because it seems the only way to understand multifaceted phenomena like work engagement and performance. In addition, by focusing on the positive aspects of the work environment and on developing employees' competences, it is more likely to trace ways of (re)designing work in a way that will lead to flourishing workforces and organizations.

\section{References}

Bacharach, S. B., Bamberger, P., \& McKinney, V. (2000). Boundary management tactics and logics of action: The case of peer-support providers. Administrative Science Quarterly, 45, 704-736.

Bakker, A. B., \& Demerouti, E. (2007). The job demandsresources model: State of the art. Journal of Managerial Psychology, 22, 309-328.

Bakker, A. B., Demerouti, E., \& Verbeke, W. (2004). Using the job demands-resources model to predict burnout and performance. Human Resource Management, 43, 83-104.

Bandura, A. (1989). Human agency in social cognitive theory. American Psychologist, 44, 1175-1184.

Bandura, A. (1997). Self-efficacy: The exercise of control. New York: Freeman.

Bandura, A. (2000). Cultivate self-efficacy for personal and organizational effectiveness. In E. A. Locke (Ed.), Handbook of principles of organizational behavior (pp. 120 136). Oxford, United Kingdom: Blackwell.

Baron, R. M., \& Kenny, D. A. (1986). The moderatormediator variable distinction in social psychological research: Conceptual, strategic, and statistical considerations. Journal of Personality and Social Psychology, 51, 1173-1182.

Beal, D. J., Weiss, H. M., Barros, E., \& MacDermid, S. M. (2005). An episodic process model of affective influences on performance. Journal of Applied Psychology, 90, 1054-1068.

Borman, W. C., \& Motowidlo, S. J. (1997). Task performance and contextual performance: The meaning for personnel selection research. Human Performance, 10, 99-109.
Bowling, N. A., Beehr, T. A., \& Swader, W. M. (2005). Giving and receiving social support at work: The roles of personality and reciprocity. Journal of Vocational Behavior, 67, 476-489.

Cropanzano, R., \& Wright, T. A. (2001). When a "happy" worker is really a "productive" worker: A review and further refinement of the happy-productive worker thesis. Consulting Psychology Journal: Practice and Research, 53, 182-199.

Daniels, K., \& Harris, C. (2005). A daily diary study of coping in the context of the job demands-control-support model. Journal of Vocational Behavior, 66, 219-237.

Deci, E. L., \& Ryan, R. M. (1985). Intrinsic motivation and self-determination in human behavior. New York: Plenum Press.

Demerouti, E., Bakker, A. B., Nachreiner, F., \& Schaufeli, W. B. (2001). The job demands-resources model of burnout. Journal of Applied Psychology, 86, 499-512.

Fried, Y., \& Ferris, G. R. (1987). The validity of the job characteristics model: A review and meta-analysis. Personnel Psychology, 40, 287-322.

Gagné, M., \& Deci, E. L. (2005). Self-determination theory and work motivation. Journal of Organizational Behavior, 26, 331-326.

George, J. M. (1991). State or trait: Effects of positive mood on prosocial behaviors at work. Journal of Applied Psychology, 76, 299-307.

Gist, M. E., \& Mitchell, T. R. (1992). Self-efficacy: A theoretical analysis of its determinants and malleability. Academy of Management Review, 17, 183-211.

Goodman, S. A., \& Svyantek, D. J. (1999). Personorganization fit and contextual performance: Do shared values matter. Journal of Vocational Behavior, $55,254-275$.

Guzzo, R. A., \& Dickson, M. W. (1996). Teams in organizations: Recent research on performance and effectiveness. Annual Review of Psychology, 47, 307-338.

Hackman, J. R., \& Oldham, G. R. (1980). Work redesign. Reading, MA: Addison Wesley.

Harter, J. K., Schmidt, F. L., \& Hayes, T. L. (2002). Business-unit-level relationship between employee satisfaction, employee engagement, and business outcomes: A meta-analysis. Journal of Applied Psychology, 87, $268-279$.

Helmreich, R. L., \& Wilhelm, J. A. (1991). Outcomes of crew resource management training. International Journal of Aviation Psychology, 14, 287-300.

Heuven, E., \& Bakker, A. B. (2003). Emotional dissonance and burnout among cabin attendants. European Journal of Work \& Organizational Psychology, 12, 81-100.

Heuven, E., Bakker, A. B., Schaufeli, W. B., \& Huisman, N. (2006). The role of self-efficacy in performing emotion work. Journal of Vocational Behavior, 69, 222-235.

Hobfoll, S. E. (1989). Conservation of resources: A new attempt at conceptualizing stress. American Psychologist, 44, 513-524.

Hobfoll, S. E. (2002). Social and psychological resources and adaptation. Review of General Psychology, 6, 307-324.

House, J. S. (1981). Work stress and social support. Addison Wesley: London.

Hox, J. (2002). Multilevel analysis: Techniques and applications. Erlbaum, Publishers: London.

Ilies, R., Schwind, K. M., \& Heller, D. (2007). Employee 
well-being: A multilevel model linking work and nonwork domains. European Journal of Work \& Organizational Psychology, 16, 326-341.

Karasek, R. A. (1985). Job content instrument: Questionnaire and user's guide (rev. 1.1). Los Angeles: University of Southern California.

Llorens, S., Bakker, A. B., Schaufeli, W. B., \& Salanova, M. (2006). Testing the robustness of the job demandsresources model. International Journal of Stress Management, 13, 378-391.

Llorens, S., Schaufeli, W. B., Bakker, A. B., \& Salanova, M. (2007). Does a positive gain spiral of resources, efficacy beliefs and engagement exists? Computers in Human Behavior, 23, 825-841.

Lubbers, R., Loughlin, C., \& Zweig, D. (2005). Young workers' job self-efficacy and affect: Pathways to health and performance. Journal of Vocational Behavior, 67, 199-214

Luthans, F., Avey, J. B., Avolio, B. J., Norman, S. M., \& Combs, G. M. (2006). Psychological capital development: Toward a micro-intervention. Journal of Organizational Behavior, 27, 387-393.

Mathieu, J. E., \& Taylor, S. R. (2006). Clarifying conditions and decision points for mediational type inferences in organizational behavior. Journal of Organizational Behavior, 27, 1031-1056.

Parker, S. K. (1998). Enhancing role-breadth self-efficacy: The roles of job enrichment and other organizational interventions. Journal of Applied Psychology, 83, $835-852$.

Rashbash, J., Browne, W., Healy, M., Cameron, B., \& Charlton, C. (2000). MLwiN (Version 1.10.006): Interactive software for multilevel analysis. London: Multilevel Models Project, Institute of Education, University of London.

Saks, A. M. (1995). Longitudinal field investigation of the moderating and mediating effects of self-efficacy on the relationship between training and newcomer adjustment. Journal of Applied Psychology, 80, 211-225.

Salanova, M., Agut, S., \& Peiró, J. M. (2005). Linking organizational resources and work engagement to employee performance and customer loyalty: The mediation of service climate. Journal of Applied Psychology, 90, $1217-1227$.

Schaufeli, W. B., \& Bakker, A. B. (2004). Job demands, job resources, and their relationship with burnout and engagement: A multi-sample study. Journal of Organizational Behavior, 25, 293-315.

Schaufeli, W. B., Bakker, A. B., \& Salanova, M. (2006a). The measurement of work engagement with a short ques- tionnaire: A cross-national study. Educational and Psychological Measurement, 66, 701-716.

Schaufeli, W. B., \& Salanova, M. (2007). Work engagement: An emerging psychological concept and its implications for organizations. In S. W. Gilliland, D. D. Steiner, \& D. P. Skarlicki (Eds.), Research in social issues in management (Vol. 5): Managing social and ethical issues in organizations (pp. 135-177). Greenwich, CT: Information Age Publishers.

Schaufeli, W. B., Salanova, M., González-Romá, V., \& Bakker, A. B. (2002). The measurement of engagement and burnout: A two sample confirmatory factor analytic approach. Journal of Happiness Studies, 3, 71-92.

Schaufeli, W. B., Taris, T. W., \& Bakker, A. B. (2006b). Dr. Jeckyll and Mr. Hyde: On the differences between work engagement and workaholism. In R. J. Burke (Ed.), Research companion to working time and work addiction (pp. 193-217). Northhampton, United Kingdom: Edward Elgar.

Schwarzer, R., \& Jerusalem, M. (1995). Generalized SelfEfficacy scale. In J. Weinman, S. Wright, \& M. Johnston (Eds.), Measures in health psychology: A user's portfolio. Causal and control beliefs (pp. 35-37). Windsor, United Kingdom: NFER-NELSON.

Sonnentag, S. (2003). Recovery, work engagement, and proactive behavior: A new look at the interface between nonwork and work. Journal of Applied Psychology, 88, $518-528$

Stajkovic, A. D., \& Luthans, F. (1998). Self-efficacy and work-related performance: A meta-analysis. Psychological Bulletin, 124, 240-261.

Viswesvaran, C., Schmidt, F. L., \& Ones, D. S. (2005). Is there a general factor in ratings of job performance? A meta-analytic framework for disentangling substantive and error influences. Journal of Applied Psychology, 90, $108-131$

Wright, T. A., \& Cropanzano, R. (2000). The role of organizational behavior in occupational health psychology: A view as we approach the millennium. Journal of Ocсиpational Health Psychology, 5, 5-10.

Yeo, G. B., \& Neal, A. (2004). A multilevel analysis of effort, practice, and performance: Effects of ability, conscientiousness, and goal orientation. Journal of Applied Psychology, 89, 231-247.

Received May 8, 2007

Revision received December 26, 2007 Accepted February 24, 2008 